\title{
Some observations of the effects of stress upon cortico-steroid excretion rates in the urine of scuba divers'
}

\author{
M. HAMMERTON AND MARY C. LOBBAN \\ APPLIED PSYCHOLOGY RESEARCH UNIT, CAMBRIDGE, ENGLAND
}

\begin{abstract}
Urine samples were obtained from scuba divers before and after dives, and on a control day. The samples were analyzed for 17-keto steroids, ketogenic (17-OH) corticosteroids, and for $\mathrm{K}, \mathrm{Cl}$ and $\mathrm{Na}$. Changes in excretion rates for these were correlated with various stress measures. Only two of these were significant $(p<.05)$, and it is concluded that excretion rates of these cortico-steroids do not constitute a sufficiently sharp measure for moderate degrees of stress.
\end{abstract}

Interest in conditions of stress has been growing for some years, and it is generally agreed that sharper criteria are desirable for determining the nature and degree of particular stresses. In this context, attention has been drawn to changes in the excretion rates of certain cortico-steroids in stressful conditions. Selye (1950) listed investigations in which significant increases in the excretion rates of the 17-Keto steroids and the Ketogenic 17-OH corticosteroids in urine were correlated with stress.

In practical situations it is rare to find only a single stress operating. It is usual, e.g., for some "physical" stress, such as excessive heat, to be combined with some "mental" stress, such as anxiety (the words "mental" and "physical" are used without any Cartesian commitment). In the present investigation, a situation, namely scuba diving, was studied in which a variety of stresses operate simultaneously. (Scuba diving is free-swimming diving in which the swimmer carries his own Self-Contained Underwater Breathing Apparatus.)

Scuba diving, on a purely physical level, is cold, even when wearing the essential wet-suit. On a mental level, there may be more or less anxiety, as a small but finite risk is involved. These categories may be said to be "mixed" in the effects of breathing at high pressure, and moving in very poor visibility. (Readers whose experience is limited to the Mediterranean in summer should know that, at a depth of $20 \mathrm{~m}$ in English water in April, it is sometimes impossible to see one's outstretched hand.) It would be an exaggeration to assert that any of these stresses are, as a rule, subjectively apprehended as "severe"; but their presence is certainly felt.

The overall effect of these was observed; and an attempt was made to compare the effects of the several factors.

One of the authors (MH) is a member of the Cambridge University Underwater Exploration Group; and the cooperation of the group was secured to provide experimental Ss on two occasions. The first was at Dale, in Pembrokeshire, South Wales, at Easter, 1966; the second was at Skomer Island, off the Pembrokeshire coast, in June, 1966.

Method

The rate of excretion of the urinary steroids shows a regular diurnal variation (Bartter et al, 1962). It is therefore important to obtain experimental and control samples at the same time (as nearly as possible), and when excretion rates are changing slowly. Therefore, the afternoon diving session was used for experimental purposes, and a specimen was also obtained from each $S$ on the afternoon of a day whereon he did not dive. On experimental afternoons, a specimen was obtained at the last convenient moment before $\mathrm{S}$ donned his equipment, and another as soon as possible after he emerged. The time of production of each specimen, and its accumulation time, were recorded in all cases, as were S's oral temperature immediately before entering and immediately after leaving the sea, the duration of the dive, and the depth attained. The S's experience was also recorded, the experimental dive being his Nth open-sea dive: $\mathrm{N}$ varied from 1 to 140 in the S population. Altogether 13 Ss took part, 7 in the April dive and 6 in the June dive, and a total of 17 experimental dives was made.

Each specimen was sealed in a polythene flask, and preserved with a small quantity of Toluene. They were subsequently analyzed by one author (MCL), without knowing which numbered specimens were control, which predive, and which postdive. For each specimen there were measured the mean rates of excretion of (i) water $\left(\mathrm{H}_{2} \mathrm{O}\right)$, (ii) Potassium (K), (iii) Sodium (Na), (iv) Chlorine (C1), (v) 17-Ketosteroids (17KS) and (vi) the Ketogenic (i.e. 17-Hydroxy) Corticosteroids (17OHCS), K and Na were analyzed by flame photometry; C1 by electrometric titration (Sanderson $1952)$; and the $17 \mathrm{KS}$ and $17 \mathrm{OHCS}$ by modifications of Norymberski's (1953) method.

Results

The mean time of acquisition of control specimens was $1631 \mathrm{~h}$, of predive specimens was $1557 \mathrm{~h}$, and of postdive specimens $1711 \mathrm{~h}$.

Tables 1 and 2 give the mean rates of excretion of water and of the electrolytes and steroids listed above.

In Table 1, t tests show that only one difference between all possible pairs within columns is signifi- 
Table 1.

Mean values of excretary rates of water and electrolytes for all Ss.

\begin{tabular}{lcccc} 
& $\begin{array}{c}\mathrm{H}_{2} \mathrm{O} \\
(\mathrm{ml} / \mathrm{min})\end{array}$ & $\begin{array}{c}\mathrm{K} \\
(\mu \mathrm{mol} / \mathrm{min})\end{array}$ & $\begin{array}{c}\mathrm{Na} \\
(\mu \mathrm{mol} / \mathrm{min})\end{array}$ & $\begin{array}{c}\mathrm{Cl} \\
(\mu \mathrm{mol} / \mathrm{min})\end{array}$ \\
\hline Control & 1.37 & 42 & 137 & 124 \\
Predive & 0.64 & 44 & 104 & 107 \\
Postdive & 0.91 & 52 & 133 & 142 \\
\hline
\end{tabular}

cant. The water excretion of controls is significantly ( $p<.05$, one-tailed) greater than that of predives. This single difference is due to three very high values of the second (June) group of controls, which could easily have been caused by drinking the well-water on Skomer Island.

In Table 2, again, only one difference is significant. For the 17-OHCS, postdive rates are higher than predive $(p<.05$, two-tail).

No significant differences of any kind emerged between the April Ss and those tested in June.

For each $\mathrm{S}$, the absolute and the percentage change in excretion rates before and after dives was calculated for 17-KS and 17-OHCS, and the Ss were ranked for these values. It was argued that, if this change were influenced by stress, then it should increase with the change in oral temperature $\theta$, with the duration of the dive $t$, and with the depth of the dive $d$. On the other hand, it should decrease with $N$, where a given dive is S's Nth. The term $\frac{\operatorname{td} \theta}{N}$ was computed for each $S$; and Spearman's rho was used for the correlation between this quantity and the change in excretion rates. It was found that the rhos for absolute and percentage change of $17-\mathrm{KS}$ rates were $+.54(p<.05$, two-tail) $\&+.52$ ( $p<.05$, two-tail $)$ respectively. Neither rho for 17-OHCS was significant at the .05 level.

The values of rho were also computed for correlations between changes in excretion rates and the several components of the term $\frac{\operatorname{td} \theta}{N}$; but none was significant at the .05 level.

\section{Discussion and Conclusions}

The conditions of the April and June dives were markedly different. In April the winds were around Force 6; air temperature was around $1^{\circ} \mathrm{C}$; water temperature was around $4^{\circ} \mathrm{C}$; and underwater visibility was negligible below $15 \mathrm{~m}$. In June the winds were light; air temperature was around $20^{\circ} \mathrm{C}$; water tem-
Table 2.

Means and SDs of rates of excretion of 17-KS and 17-OHCS for all Ss.

\begin{tabular}{lccccc} 
& \multicolumn{2}{c}{ 17-KS } & & \multicolumn{2}{c}{$17-$ OHCS } \\
\cline { 2 - 3 } \cline { 5 - 6 } & Means & SDs & & Means & SDs \\
\hline Controls & 8.37 & 3.02 & 9.96 & 5.56 \\
Predive & 6.29 & 3.96 & 8.30 & 4.89 \\
Postdive & 8.27 & 3.85 & 11.80 & 7.18 \\
\hline
\end{tabular}

perature was above $15^{\circ} \mathrm{C}$; and underwater visibility exceeded $2 \mathrm{~m}$ at a depth of $20 \mathrm{~m}$. It is thus remarkable both that the effects found in these experiments were slight, despite the severe conditions in April, and that they were practically constant despite the pleasanter conditions in June.

It is known (Baddeley, 1966) that manual dexterity decreases with depth; and divers' pulse-rates increase before entering the water (Baddeley, personal communication to the authors, 1967). Both of these facts are consistent with the subjective feelings of stress that most divers report.

The stresses experienced by the Ss in this experiment, in which depths of 10-30 m were reached for periods of up to half an hour, were described by Ss as moderate. It seems, then, that Keto- and Ketogenic steroid excretion rates do not constitute a sufficiently sharp measure for such moderate degrees of stress.

This conclusion, though perhaps disappointing, is not unimportant. It leaves open the question of the utility of such measures in more extreme states of stress.

\section{References}

BADDELEY, A. D. Influence of depth on the manual dexterity of divers. J. appl. Psychol, 1966, 50, 81-85.

BARTTER, F. C., DELEA, C. S., \& HALBERG, F. A map of urinary changes related to circadian variations in adrenal cortical function in normal subjects. Annal. N. Y. Acad. Sci., 1962, 98, 969-983.

NORYMBERSKI, J. K., STUBBS, R. O., \& WEST, H. F. Assessment of adrenocortical activity by assay of 17 ketogenic steroids in urine. Lancet, 1953, I, 1276-1281.

SANDERSON, P. H. Potentiometric determination of chloride in biological fluids. Biochem. J., 1952, 52, 502-505.

SELYE, H. Stress. Montreal: Acta Inc., 1950.

Note

1. The authors are grateful for the friendly cooperation of members of the Cambridge University Underwater Exploration Group. They are also indebted to the Department of Chemical Pathology, Hospital for Sick Children, Great Ormond Street, London, W.C.1., for help and advice relating to steroid analysis. 